\title{
Electrocatalyst $\square$ composed of $\llbracket$ Platinum Nanoparticles Deposited on Doubly Polymer-coated Carbon Nanotubes shows a High CO-tolerance in Methanol Oxidation Reaction
}

ZehuiYang $^{\mathrm{a}, \mathrm{d}}$, Akiyo Nagashima ${ }^{\mathrm{a}}$, TsuyohikoFujigaya ${ }^{\mathrm{a}, \mathrm{b}}$ and NaotoshiNakashima ${ }^{\mathrm{a}, \mathrm{b}, \mathrm{c}^{*}}$
${ }^{a}$ Department of Applied Chemistry, Graduate School of Engineering, Kyushu University, 744 Motooka, Nishi-ku, Fukuoka 819-0395, Japan

${ }^{b}$ International Institute for Carbon Neutral Energy Research (WPI-I2CNER), Kyushu University, Fukuoka 819-0395, Japan

${ }^{c}$ Core Research for Evolutionary Science and Technology (CREST), Japan Science and Agency (JST), 5 Sanbancho, Chiyoda-ku, Tokyo, 102-0075, Japan

${ }^{d}$ Sustainable Energy Laboratory, Faculty of Materials Science andChemistry, China University of Geosciences Wuhan, 388 Lumo RD, Wuhan, 430074, China

To whom correspondence should be addressed:

Tel/Fax: +81 092-802-2840;E-mail:nakashima-tcm@mail.cstm.kyushu-u.ac.jp

(C) 2016. This manuscript version is made available under the Elsevier user license 


\section{Abstract}

High CO-tolerance and durability of anodic fuel cell electrocatalystsis one of the important factors for commercialization of direct methanol fuel cells (DMFCs). In this study, we describe the preparation ofan electrocatalyst composed ofpoly[2,2'-(2,6-pyridine)-5,5'-bibenzimidazole] (PyPBI) and poly(vinylphosphonic acid) (PVPA)coated multi-walled carbon nanotubes (MWNTs) on which $\sim 3 \mathrm{~nm} \mathrm{Pt}$ nanoparticles (Pt-NPs) are deposited.The fabricated electrocatalyst shows 1.5-times higher $\mathrm{CO}$ tolerance compared to the commercial $\mathrm{CB} / \mathrm{Pt}$, which would be due to the wrapping of the CNTs with PVPA by the aidof PyPBI. Meanwhile, the electrocatalyst almost maintainsitsinitial electrochemical surface area (ECSA) and mass activity during the methanol oxidation reaction (MOR) after 10,000 potential cyclingin the range of1 1.5 V vs. RHE. In contrast, the commercial CB/Pt shows almost a50\% loss in its ECSA and mass activity. These results indicate that the durability of the newly fabricated electrocatalyst is quite high and theobtained high CO-toleranceand durabilityare important for the design of anelectrocatalyst for DMFC applications.

Keywords:Carbon nanotubes;Electrocatalyst; CO tolerance; Direct methanol fuel cells;

Polymer-coated carbon nanotubes. 


\section{Introduction}

The global energy crisis has forced us to develop sustainable energy sources and polymer electrolyte fuel cells (PEFCs)that have attractedmuch attention due to their higher energy conversion efficiency, environmental friendliness and lower operatingtemperature. [1-3]Based on the different phasein the fuel, PEFCs are classified as hydrogen PEFCs and direct liquid fuel cells, which feed hydrogen and liquid fuels to the anode, respectively. Liquid fuels, such as borohydride[4-9] and methanol, received considerable attention because of easy storage and transportation compared to hydrogen.In Direct methanol fuel cells (DMFCs), the methanol oxidation reaction (MOR) offers an almost comparable cell voltage $(1.19 \mathrm{~V})$ to that of the hydrogen oxidation reaction $(\mathrm{HOR}, 1.23 \mathrm{~V})$. $[10,11]$ The DMFCs can be used as portable energy sources for electronic products due to their easy storage and high energy density $(5.04 \mathrm{KWh}$ $\left.\mathrm{L}^{-1}\right)$ [12-14], whilethe DMFCs face three serious anodic problems; namely, i) CO poisoning of the electrocatalyststhat is induced by the incomplete MOR[15-17] ii) low durability in the electrocatalysts due to the use of carbon black as the platinum (Pt) support in the commercial $\mathrm{CB} / \mathrm{Pt}[18]$,and iii) a sluggish MOR[19].

Many researchers have tried to separately solve three problems. Alloying Pt with

some transition metals (Ru, [20-22] Au, [23, 24]Sn, [16, 25]) was found to enhance the 
$\mathrm{CO}$ tolerance of the electrocatalysts due to their lower potential for forming the $\mathrm{M}-\mathrm{OH}$ species, which react with the Pt-CO to remove $\mathrm{CO}$ from the Pt surfaces, while the transition metals are easily dissolved in the acidic medium, which is the practical environment in the real DMFC operation due to the use of Nafion membranes. Changing the Pt support to carbon nanotubes (CNTs), [7, 26, 27]graphene [28-30]or metal oxides[20, 31, 32] has proved to providea higher durability. Also, we reported that the CO tolerance and durability of the electrocatalyst are simultaneously enhanced after coating with poly(vinylphosphonic acid) (PVPA) assisted by the poly[2,2'-(2,6-pyridine)-5,5'-bibenzimidazole] (PyPBI) due to the acid-base interaction between the $-\mathrm{OH}$ groups of PVPA and -NH groups on PyPBI. [18, 33, 34]The enhanced CO tolerance and durability is considered to bethat the phosphorus on the PVPA weakened the binding energy between the Pt and CO species andthe Pt-NPs sandwich structures, respectively.Nevertheless, the mass activity of the coated electrocatalyst decreased by $35 \%$ due to the coverage of the Pt-NPs by the PVPA, which negatively affected the methanol adsorption on the Pt surfaces.[33]Thus, coating the Pt-NPs with PVPA did not enhance the sluggish MOR. 


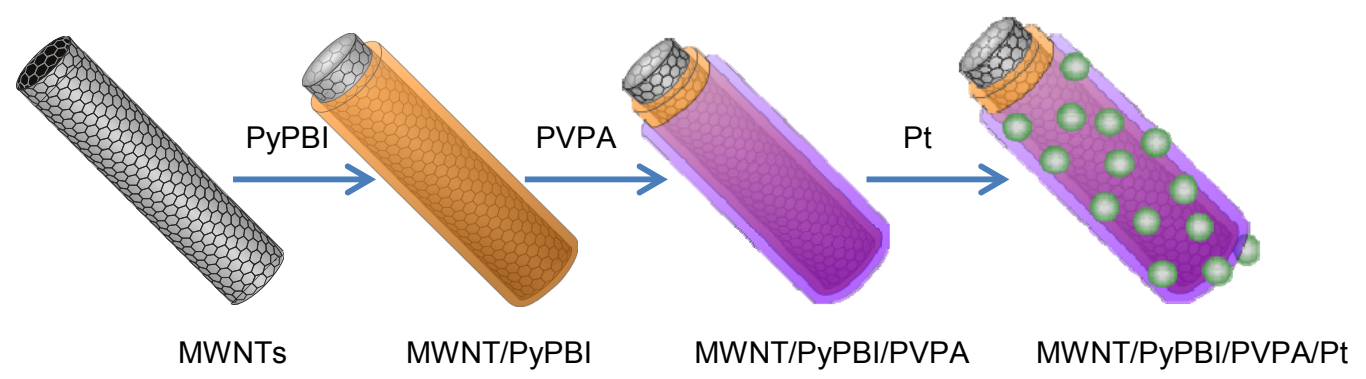

Fig. 1.Schematic illustration for the preparation of the MWNT/PyPBI/PVPA/Pt

electrocatalyst.

In this study, we synthesizedaPt electrocatalyst that was deposited on doubly-polymer-coated multi-walled carbon nanotubes (MWNTs) as shown in Fig. 1, in which the MWNTs are coated with PyPBI and then with PVPA. Briefly, the MWNTs were dispersed in a solvent by the aid of PyPBI due to the $\pi-\pi$ interaction between the MWNTs and the PyPBI[35, 36],then coated with the PVPA based on the acid-base interaction. Finally, the Pt-NPs were deposited onto the surfaces of the doubly polymer-coated MWNTs. Importantly, the Pt-NPs are not covered by any polymersin this structure and the PVPA in the electrocatalyst is expected to enhance the CO tolerance of the electrocatalyst. The $\mathrm{CO}$ tolerance during the MOR of the synthesized electrocatalyst was compared with that of the commercial $\mathrm{CB} / \mathrm{Pt}$ and the previously reported MWNT/PyPBI/Pt/PVPA. [37] 


\section{Experimental section}

\section{Materials and reagents}

2-Propanol, hydrogen hexachloroplatinatehexahydrate $\left(\mathrm{H}_{2} \mathrm{PtCl}_{6} \cdot 6 \mathrm{H}_{2} \mathrm{O}\right)$, ethylene glycol (EG), N,N-dimethylacetamide (DMAc) and PVPA (30 wt $\%$ ) were purchased from Wako Pure Chemical Co., Ltd. The MWNTs with an20nm diameter were provided by the Nikkiso Corp. The Pt-NPs-deposited CB (CB/Pt) catalyst was purchased from

Tanaka Kikinzoku Kogyo K. K., in which the Pt loading on the CB was 37.5 wt\%.A Nafion solution (5 wt\%), perchloric acid $\left(\mathrm{HClO}_{4}, 70 \%\right)$ and methanolwerepurchased from Sigma-Aldrich, EMD Millipore Chemical Co., Ltd., and Kanto Chemical Co., Inc., respectively.Poly[2,2'-(2,6-pyridine)-5,5'-bibenzimidazole] (PyPBI) was synthesized according to aprevious report.[38]TheMilli-Q water(18.2 $\mathrm{M} \Omega \mathrm{cm})$ was used to prepare the solutions during all the experiments and all the chemicals were used as received without any furtherpurification.

\section{Synthesis of MWNT/PyPBI/PVPA/Pt}

Briefly, the MWNTs (10 mg)were dispersed in DMAc $(20 \mathrm{~mL})$ to which10 $\mathrm{mg}$ of the PyPBI dissolved in $10 \mathrm{~mL}$ of DMAcwas added at room temperature, then sonicatedfor 1 h to obtain a solution of the composite, MWNT/PyPBI, which was then collected by filtrationfollowed by rinsing with DMAc. The obtained black powder was dried under 
vacuum overnight at $60{ }^{\circ} \mathrm{C}$ to completely remove the solvent. MWNT/PyPBI(10 mg) was dispersed in an EG aqueous solution $(v / v=3: 2)$ to which 1 mLof the PVPA (30 wt $\%)$ was added and stirred for $10 \mathrm{~min}$. The mixture was filtered and dried under vacuum overnight at $60{ }^{\circ} \mathrm{C}$. Finally, the Pt loading was carried out by the reduction of the $\mathrm{H}_{2} \mathrm{PtCl}_{6} \cdot 6 \mathrm{H}_{2} \mathrm{O}$ in an EG aqueous solution $(v / v=3: 2)$ at $140{ }^{\circ} \mathrm{C}$ for 30 min under an $\mathrm{N}_{2}$ atmosphere. The obtained product was filtered, washed, then dried overnight under vacuum at $60{ }^{\circ} \mathrm{C}$ to obtain the MWNT/PyPBI/PVPA/Pt.

\section{Materials Characterization}

The X-ray photoelectron spectroscopy (XPS) was carried outusing an AXIS-ULTRA $^{\text {DLD }}$ (Shimadzu) instrument. The pressure in the XPS analysis chamber was maintained at $10^{-9} \mathrm{~Pa}$. For the calibration process, the binding energy (BE) of the core level $\mathrm{C}_{1 \mathrm{~s}}$ peak was fixed at $284.5 \mathrm{eV}$. Thermogravimetric analysis (TGA) measurements were conducted using aTGA analyzer (EXSTAR 6000, Seiko, Inc.)at the heating rate of $10{ }^{\circ} \mathrm{Cmin}^{-1}$ and $100 \mathrm{mLmin}^{-1}$ air-flow. The TEM imageswere obtained using a JEM-2010 (JEOL, acceleration voltage of $120 \mathrm{kV}$ ) electron microscope. A copper grid with a carbon support (Okenshoji Co., Ltd.) was used for the TEM observations.

\section{Electrochemical surface area measurement}


The electrochemical measurements were performed using a rotating ring disk electrode attached to an RRDE-3 (Bioanalytical Systems, Inc.) with a three-electrode configuration in a vessel at room temperature. A glassy carbon electrode (GCE) with a diameter of 4 mmwas used as the working electrode. A Pt wire and $\mathrm{Ag} / \mathrm{AgCl}(3 \mathrm{M} \mathrm{KCl})$ were used as the counter and reference electrodes, respectively. The potential of the electrode was controlled by an ALS-Model DY2323 (BAS) potentiostat. The electrocatalyst solution was typically prepared as follows. The catalyst $(1.0 \mathrm{mg})$ was ultrasonically dispersed ina 2-propanol aqueous solution $(2.0 \mathrm{~mL}, v / v=4: 1)$ to form a homogeneous suspension, which wascast on aGCE (the loading amount of $\mathrm{Pt}$ wascontrolled at $14 \mu \mathrm{gcm}^{-2}$ ), then air-dried under vacuum for $2 \mathrm{~h}$. The cyclic voltammetry $(\mathrm{CV})$ measurements of the electrocatalystat the scan rate of $50 \mathrm{mVs}^{-1}$ were carried in an $\mathrm{N}_{2}$-saturated $0.1 \mathrm{M} \mathrm{HClO}_{4}$ solution after a $13 \mathrm{CV}$-cycle pretreatment atthe scan rate of $5 \mathrm{mVs}^{-1}$ in order to activate the electrocatalyst and to obtaina stable $\mathrm{CV}$, then the electrochemical surface area (ECSA) value was determined from the average value from three measurements. All the potentials were referenced to the reference hydrogen electrode (RHE).

\section{Durability test}


The carbon corrosion was tested based on the protocol of the Fuel Cell Commercialization Conference of Japan (FCCJ)[39] (measured in $\mathrm{N}_{2}$-saturated 0.1M $\mathrm{HClO}_{4}$ at room temperature), in which the potential was heldat $1.0 \mathrm{~V} v \mathrm{~s}$. RHE for $30 \mathrm{~s}$, then increased to $1.5 \mathrm{~V}$ vs. RHE at the scan speed of $0.5 \mathrm{Vs}^{-1}$ followed by a potential-return to $1.0 \mathrm{~V}$ vs. RHE. This procedure was cycled, and after each 1,000 cycles, the ECSA measurement was carried out three times to calculate the average value (see Supporting information, Fig. S1).

\section{Methanol oxidation reaction (MOR)}

The MOR was measured before and after the durability test using an $\mathrm{N}_{2}$-saturated $0.1 \mathrm{M}$ $\mathrm{HClO}_{4}$ and $1 \mathrm{M}$ methanol solution at thescan rate of $50 \mathrm{mVs}^{-1}$ at room temperature. The electrode was the same as used for the ECSA measurement. The Pt loading on the electrode was controlled at $14 \mu \mathrm{gcm}^{-2}$. Before the MOR measurement, 50 cycles were carried out to activate the electrocatalystin order to obtain a stable curve.

\section{CO-stripping}

$\mathrm{CO}$ stripping voltammetry was performed by feeding the working electrode with $\mathrm{N}_{2}$ for $1 \mathrm{~h}$ and the activation of the electrocatalyst was carried out by $13 \mathrm{CV}$ cycles, then purged with CO gas $\left(10 \%\right.$, balanced with Ar)for 1 hatthe flow rate of $100 \mathrm{mLmin}^{-1}$, while holding the working electrode potential at $0.2 \mathrm{~V}$ vs. RHE. After the adsorption, the CO 
was removed from the electrolyte, thenchanged to $\mathrm{N}_{2}$ bubbling for $50 \mathrm{~min}$ to completely

remove the dissolved $\mathrm{CO}$ in the electrolyte. The $\mathrm{CO}$ stripping voltammogram was measuredatthe scan rate of $50 \mathrm{mVs}^{-1}$.

\section{Results and Discussion}

\section{Fundamental Characterisation of MWNT/PyPBI/PVPA/Pt}
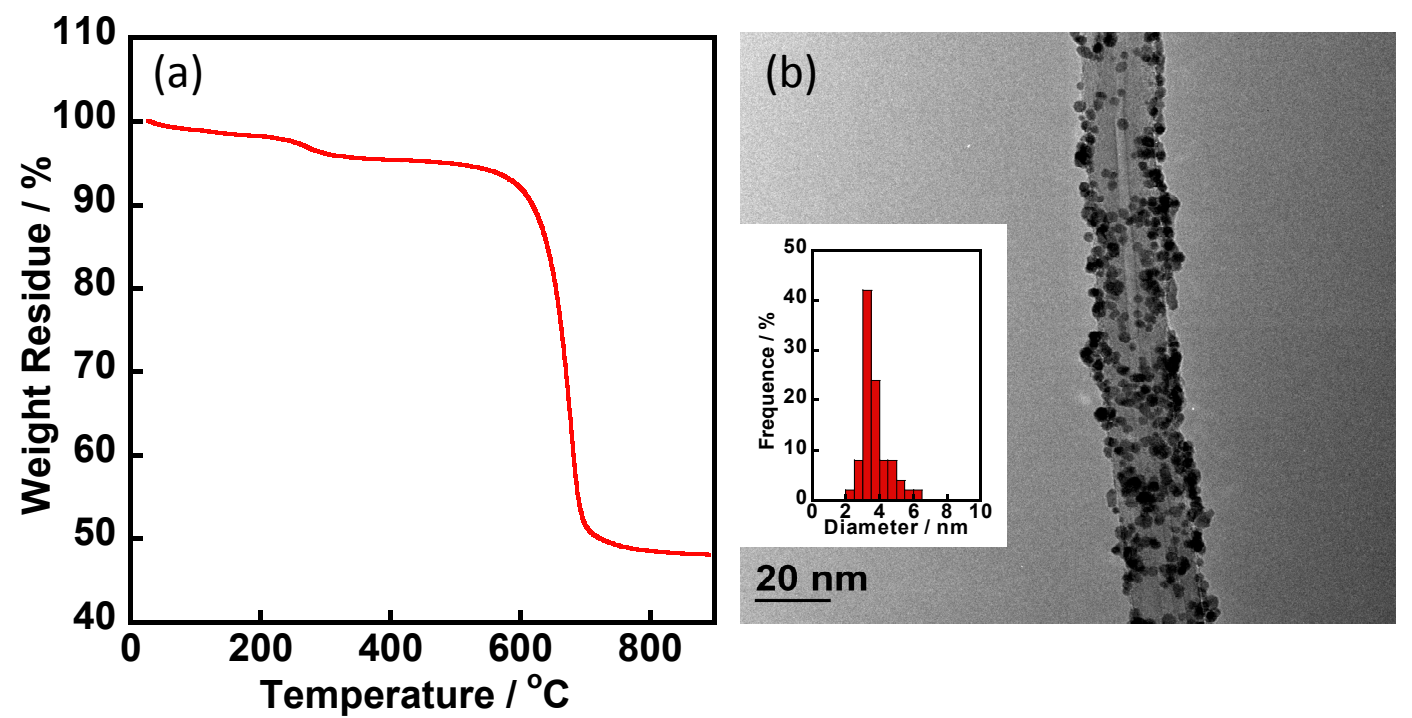

Fig. 2. (a) TGA curve of the MWNT/PyPBI/PVPA/Pt measured under flowing air $\left(100 \mathrm{mLmin}^{-1}\right)$ at the heating rate of $10{ }^{\circ} \mathrm{Cmin}^{-1}$. (b) TEM image of the MWNT/PyPBI/PVPA/Pt before the durability test.Histogram of particle size distributions (100 particles) of the MWNT/PyPBI/PVPA/Pt isshown as the inset. 

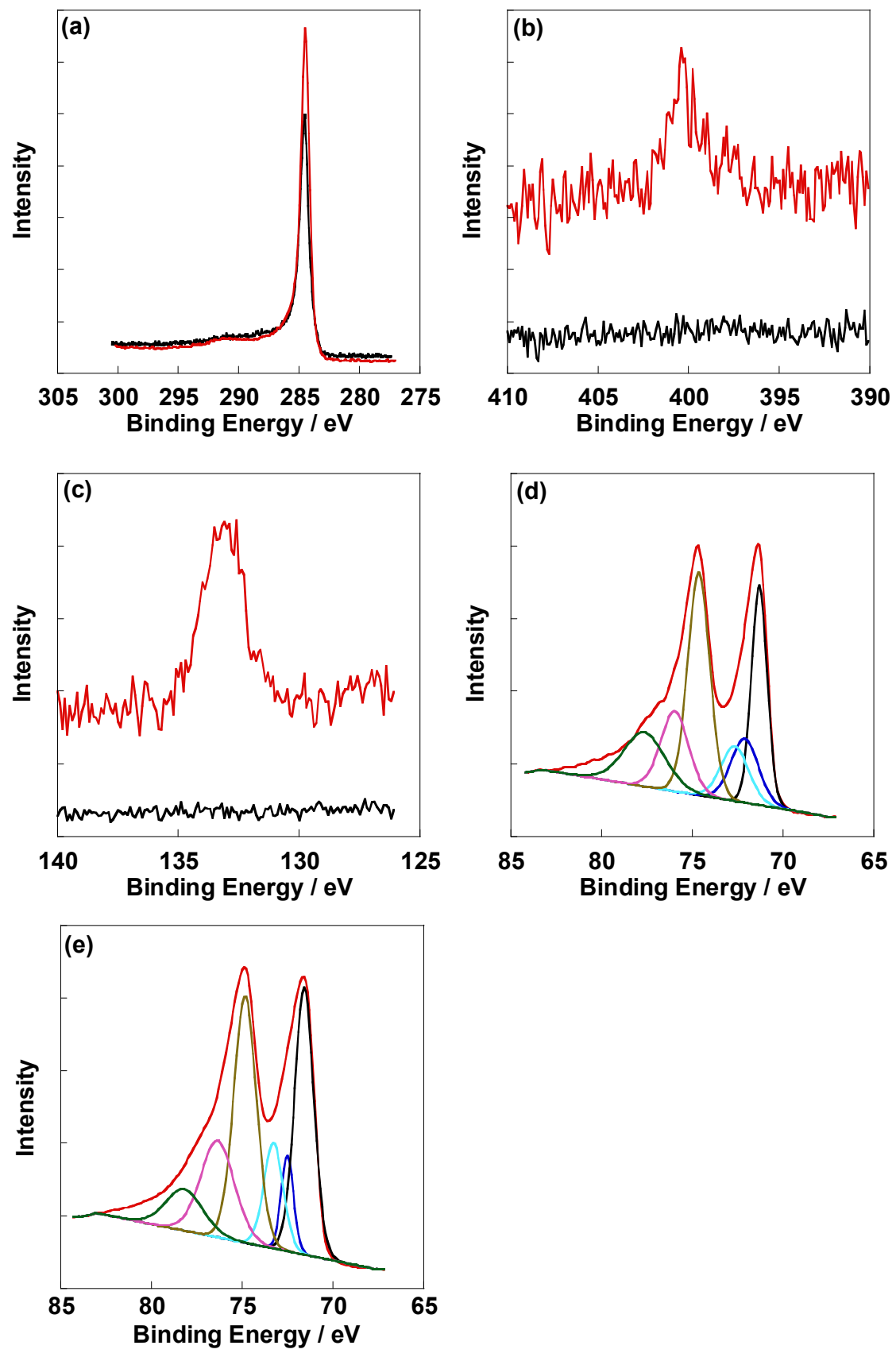

Fig. 3. XPS narrow scans of the regions of $C_{1 s}$ (a), $N_{1 s}$ (b) and $P_{2 p}$ (c) of MWNT/PyPBI/PVPA/Pt (red line) and CB/Pt (black line). XPS narrow scan of the $\mathrm{Pt}_{4 \mathrm{f}}$ region of $\mathrm{MWNT} / \mathrm{PyPBI} / \mathrm{PVPA} / \mathrm{Pt}$ (d) and $\mathrm{CB} / \mathrm{Pt}$ (e), in which the deconvolution curves areshown. 
After the synthesis of the electrocatalyst, some fundamental characterizations were carried out to evaluate the composite as shown in Fig.2 and Fig.3. From Fig.2a, the residual weight was $47 \mathrm{wt} \%$ suggesting that almost all the Pt ions were efficiently loaded on the MWNT assisted by the PyPBI due to the Pt-N bonding.[40] The weight loss starting at around $200{ }^{\circ} \mathrm{C}$ is due to the decomposition of the PVPA since the decomposition temperatures of PyPBI and MWNTsare $\sim 500{ }^{\circ} \mathrm{C}$ and $700{ }^{\circ} \mathrm{C}$, respectively. $[35,36]$ Thus, the PVPA amount in the composite was evaluated to be 3.5wt\%. Based on the weight ratio betweenthe PyPBI and MWNTs (7:93),[35] the detailed amount of each material was $3.5 \mathrm{wt} \%, 3.5 \mathrm{wt} \%$, 46wt $\%$ and $47 \mathrm{wt} \%$ for PyPBI, PVPA, MWNTs and Pt, respectively. From Fig.2b, the typical TEM image shows that the Pt-NPs (diameter $=3.2 \pm 0.5 \mathrm{~nm}$ ) are homogeneously deposited on the MWNTs (for a low magnification TEM image, see Supporting Information, Fig.S2), in which the diameter of the Pt-NP was somehow smaller than that deposited on the $\mathrm{CB}(3.9 \pm 0.6 \mathrm{~nm}$, see Supporting information, Fig. S3a). The particle size of the synthesized electrocatalyst evaluated from the XRD was $2.7 \mathrm{~nm}$ as shown in Fig. S4. The particles size calculated from the XRD is normally smaller than that from the TEM since the XRD detects the crystallized Pt. It is importantto show evidence of the existence of the PVPA in the composite (for the survey scan, see Supporting Information, Fig. S5). In 
the XPS spectra (Fig.3b), the typical $\mathrm{N}_{1 \mathrm{~s}}$ peak is observed at $400 \mathrm{eV}$, which is derived from the PyPBI[4], and the apparent peak that appeared at $132 \mathrm{eV}$ (Fig. 3c) was assigned to the $\mathrm{P}_{2 \mathrm{p}}$ peak which is derived from the PVPA,[41] suggesting a successfulcoating by the PVPA. As shown in Fig.3(d, e), the ratio of $\mathrm{Pt}(0): \operatorname{Pt}(\mathrm{II}): \operatorname{Pt}(\mathrm{IV})$ was $65.3: 15.2: 19.5$, which was similar to that of the $\mathrm{CB} / \mathrm{Pt}(57.3: 17.1: 25.6)$.

\section{Evaluation of electrochemical surface area and durability}
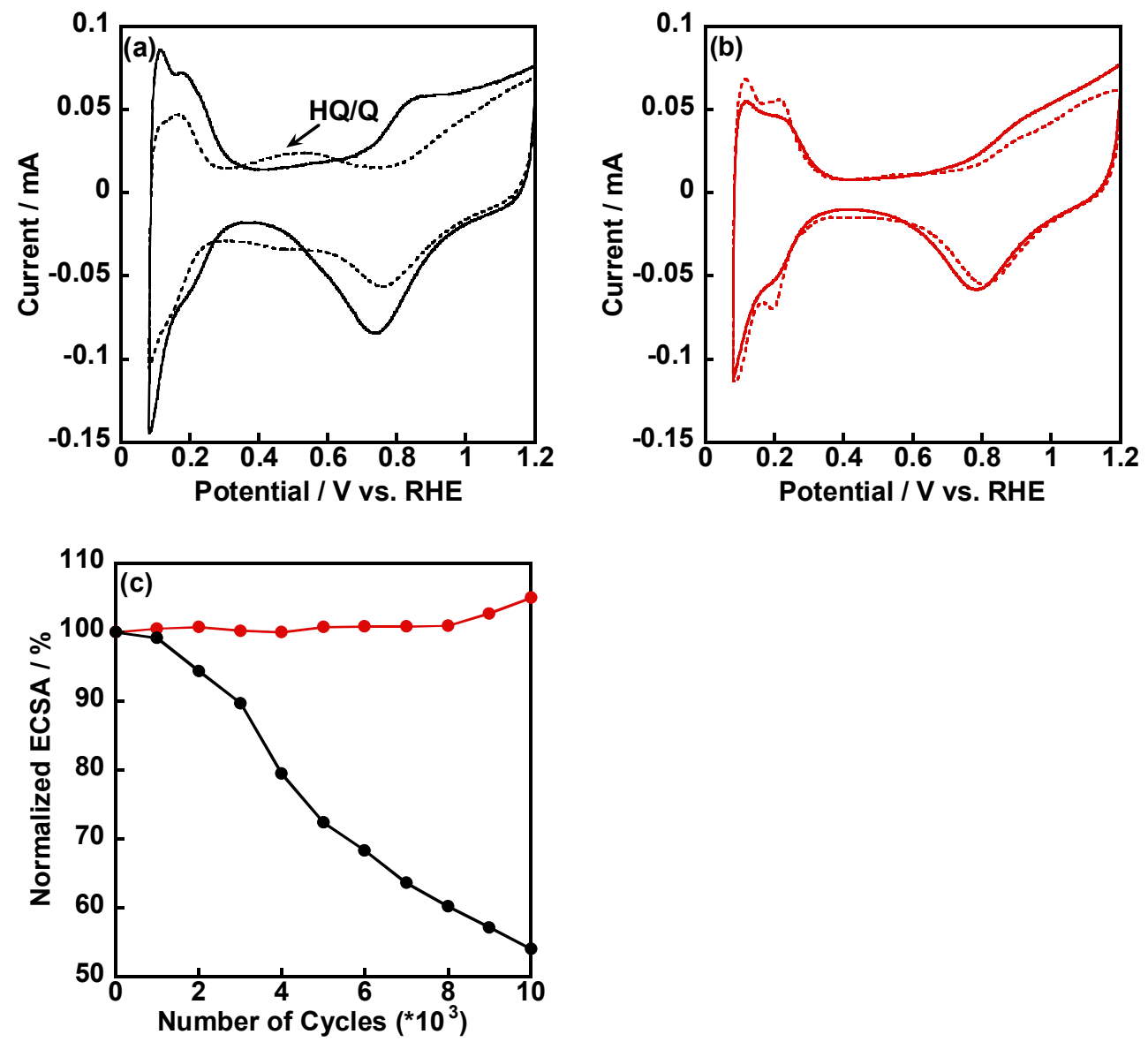

Fig. 4. $\mathrm{CV}$ curves were recorded in $0.1 \mathrm{M} \mathrm{HClO}_{4}$ at the scan rate of $50 \mathrm{mVs}^{-1}$ for CB/Pt (a) andMWNT/PyPBI/PVPA/Pt (b) before (solid line) and after (dotted line) 
the durability test. (c) Normalized ECSAs of CB/Pt (black line), and MWNT/PyPBI/PVPA/Pt (red line) as a function of the number of potential cycles in the range of $1.0 \sim 1.5 \mathrm{~V} v$ s. RHE.

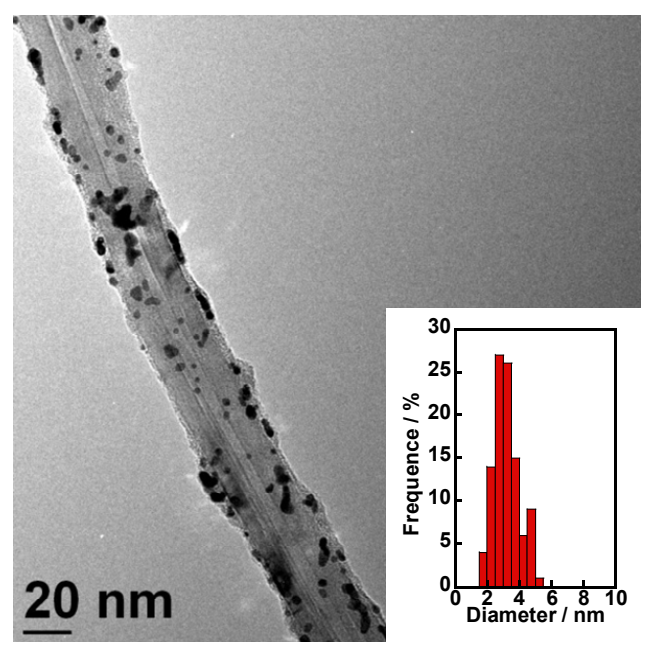

Fig. 5.TEM image of MWNT/PyPBI/PVPA/Pt after the durability test.Histogram of particle size distributions (100 particles) of MWNT/PyPBI/PVPA/Pt isshown as the inset.

The electrochemical surface area (ECSA) is an important factor to evaluate the anodic electrocatalyst, which was evaluated from the peak area due to the adsorption of hydrogen in the range of $0.1 \sim 0.4 \mathrm{~V} v$ s. RHE based on the following equation (1), $\mathrm{ECSA}=\mathrm{Q}_{\mathrm{H}} / 210 \times(\mathrm{Pt}$ loading on electrode $)$

where $\mathrm{Q}_{\mathrm{H}}$ is the charge exchanged during the electro-adsorption of hydrogen on the Pt. $[42,43]$ 
As shown in Fig. 4b, the ECSA of MWNT/PyPBI/PVPA/Pt was $50.2 \mathrm{~m}^{2} \mathrm{~g}^{-1}$, which was lower than that of $\mathrm{CB} / \operatorname{Pt}\left(60.6 \mathrm{~m}^{2} \mathrm{~g}^{-1}\right.$, Fig. $\left.4 \mathrm{a}\right)$, while it was higher than that $\left(44.7 \mathrm{~m}^{2}\right.$ $\mathrm{g}^{-1}$ ) of MWNT/PyPBI/Pt[44] due to the smaller Pt-NP size. The long-term durability of the electrocatalyst was evaluated based on the carbon corrosion test, which was carried out according to the protocol from the Fuel Cell Commercialization of Japan (see Supporting Information, Fig. S1). The potential was cycled from 1.0 to $1.5 \mathrm{~V}$ vs. RHE to accelerate the carbon corrosion causing the detachment and coalescence of the Pt-NPs. From Fig. 4a, the pronouncedhydroquinone-quinone (HQ/Q) redox peakwas observed at $0.55 \mathrm{~V}$ vs. RHE after the durability testingof the commercial $\mathrm{CB} / \mathrm{Pt}$ since the $\mathrm{CB}$ has a very low resistance toward carbon corrosion, while MWNT/PyPBI/PVPA/Pt showed a stable CV curve even after the durability testing, indicating a higher durability.[45] The ECSA was calculated after every1,000 potential cycles and the results are plotted in Fig. 4c, havingthe commercial CB/Pt showed a 46\% loss, which is in a sharp contrast to that of MWNT/PyPBI/PVPA/Pt, in whichalmost no change in the ECSA value. Also, the diameter of the Pt-NPs in MWNT/PyPBI/PVPA/Pt $(3.7 \pm 0.5 \mathrm{~nm}$, Fig. 5$)$ is almost the same as the initial size, while the Pt-NPs on CB/Pt have been reported toincreaseto $5.0 \pm 1.0 \mathrm{~nm}$ (Fig. S3b), indicating the Pt-NPs were more stable in the synthesized electrocatalyst due to the strong Pt-N bonding. 


\section{Estimation of activity and CO tolerance}
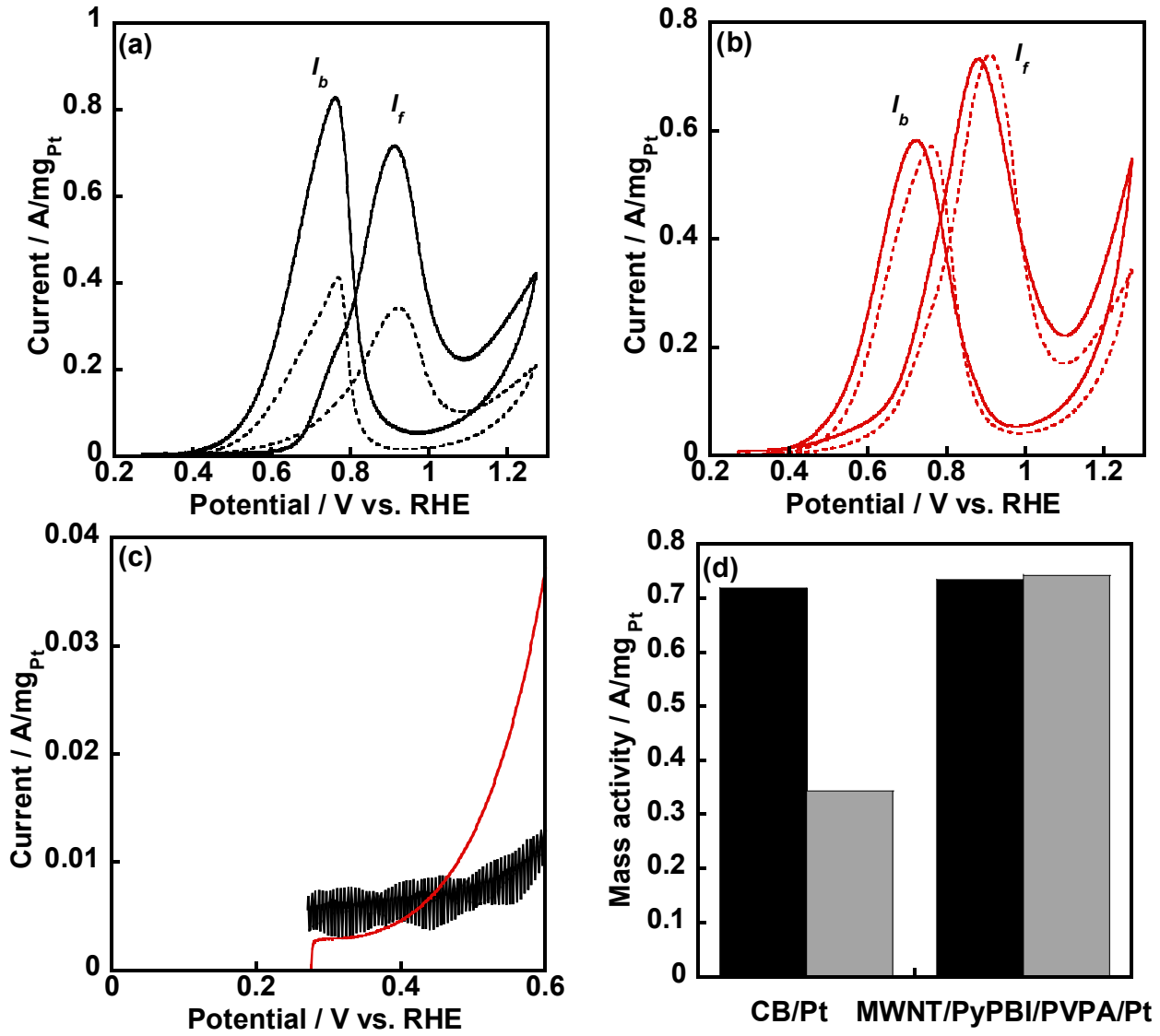

Fig. 6. Methanol oxidation reaction (MOR) curves measured in an $\mathrm{N}_{2}$-saturated

0.1 $\mathrm{M} \mathrm{HClO}_{4}$ and $1 \mathrm{Mmethanol}$ solution of $\mathrm{CB} / \mathrm{Pt}$ (a) andMWNT/PyPBI/PVPA/Pt

before (solid line) and after (dotted line) the durability test. (c) Magnification of the MOR profiles of CB/Pt (black line) and MWNT/PyPBI/PVPA/Pt (red line) in the range of $0.27 \sim 0.6 \mathrm{~V}$ vs. RHE. (d) Bar displays the mass activities of $\mathrm{CB} / \mathrm{Pt}$ and MWNT/PyPBI/PVPA/Pt before (black) and after (grey) the durability test. 


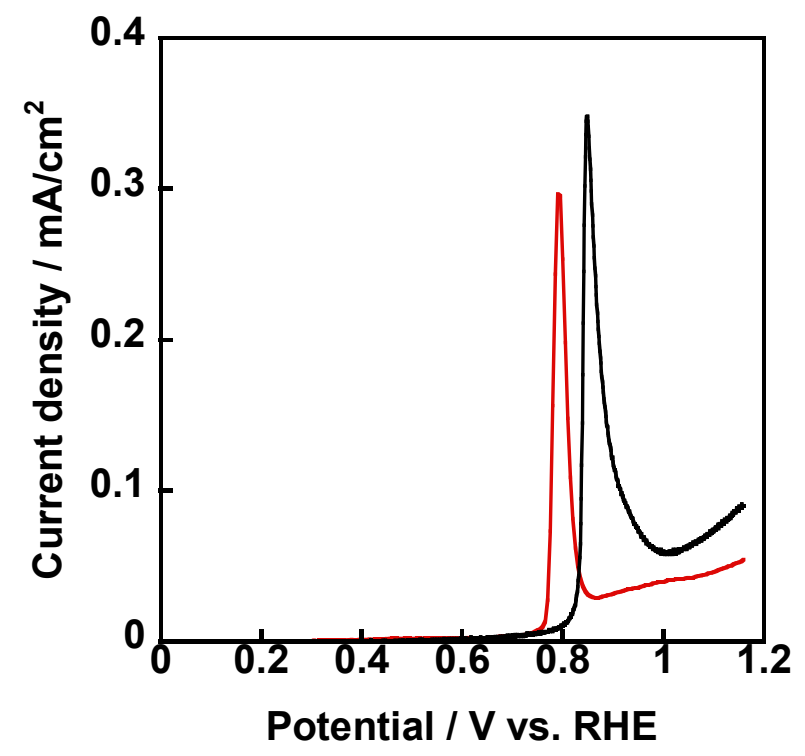

Fig. 7.First cycles of the CO stripping voltammograms of $\mathrm{CB} / \mathrm{Pt}$ (black line) and MWNT/PyPBI/PVPA/Pt (red line) at the scan rate of $50 \mathrm{mVs}^{-1}$ at $25{ }^{\circ} \mathrm{C}$.

Table 1.Comparisons of CO tolerance for $\mathrm{CB} / \mathrm{Pt}$ and MWNT/PyPBI/PVPA/Pt before and after the durability test.

\begin{tabular}{ccc}
\hline Electrocatalyst & $I_{f} / I_{b}$ (before durability) & $I_{f} I_{b}$ (after durability) \\
\hline $\mathrm{CB} / \mathrm{Pt}$ & 0.87 & 0.83 \\
$\mathrm{MWNT} / \mathrm{PyPBI} / \mathrm{PVPA} / \mathrm{Pt}$ & 1.30 & 1.26 \\
\hline
\end{tabular}

During the real fuel cell applications, the methanol is oxidized on the anodic side, while incomplete methanol oxidation generates carbon monoxide( $\mathrm{CO})$, which adsorbs ontothe Pt surface, poisons the Pt-NPs, thus leading to the deterioration of the fuel cell performance. Thus, the $\mathrm{CO}$ anti-poisoning is of importance for the anodic 
electrocatalyst for the DMFC. The MOR is carried out in a half-cell to evaluate the performance of the electrocatalyst as well as the $\mathrm{CO}$ anti-poisoning. The MOR curve is shown in Fig. 6. As indicated in the figure, two peaks that represent the anodicpeak $\left(I_{f}\right)$ and reverse anodic peak $\left(I_{b}\right)$ were observed. The $I_{f}$ peak is the oxidation of the methanol to $\mathrm{CO}_{2}, \mathrm{CO}$ and $\mathrm{HCOOH}[46,47]$ The $I_{b}$ peak is the oxidation of the $\mathrm{CO}$ and $\mathrm{HCOOH}$. The CO anti-poisoning can be estimated from the ratio of $I_{f} / I_{b}$ because the abundant by-product is CO. The higher $I_{f} / I_{b}$ ratio indicates less generation of the by-product, which denotesa higher $\mathrm{CO}$ anti-poisoning. [22, 48]The MOR was measured before and after the durability test, and the $I_{f} / I_{b}$ ratios of CB/Ptand MWNT/PyPBI/PVPA/Pt are shown in Table 1. The CO-tolerance of MWNT/PyPBI/PVPA/Pt was 1.5 times higher than that of the commercial $\mathrm{CB} / \mathrm{Pt}$ before and after the durability test. The stable $I_{f} I_{b}$ ratio of MWNT/PyPBI/PVPA/Pt suggested that the PVPA was stable during the potential cycling. Also, the $\mathrm{CO}$ stripping voltammetry is an important method to directly prove the CO-tolerance, in which the $\mathrm{CO}$ was oxidized by the electrocatalyst. As shown in Fig. 7, the sharp peak that appeared at $0.9 \mathrm{~V}$ vs. RHE was due to the oxidation of the absorbed CO species. The peak of the MWNT/PyPBI/PVPA/Pt showed a negative shift compared to that of the commercial $\mathrm{CB} / \mathrm{Pt}$, indicating that the $\mathrm{CO}$ species were more easily removed from the Pt-NP surfaces. Thus, the $I_{f} / I_{b}$ ratios from 
the MOR and CO stripping suggested that the synthesized MWNT/PyPBI/PVPA/Pt shows a higher $\mathrm{CO}$ tolerance than the commercial $\mathrm{CB} / \mathrm{Pt}$.

The sluggish MOR is also an obstacle for commercialization of the DMFC. As shown in Fig. 6c, the MOR curve of MWNT/PyPBI/PVPA/Pt showed a higher current at the initial potential compared to $\mathrm{CB} / \mathrm{Pt}$,suggesting that $\mathrm{MWNT} / \mathrm{PyPBI} / \mathrm{PVPA} / \mathrm{Pt}$ is more active during dthe MOR. The mass activity of the MOR was evaluated fromthe current of the $I_{f}$ peak. Before the durability test, MWNT/PyPBI/PVPA/Pt showed a comparable mass activity to $\mathrm{CB} / \mathrm{Pt}$, while the value of MWNT/PyPBI/PVPA/Pt was two times higher than that of MWNT/PyPBI/Pt/PVPA, in which the PVPA-coating was carried out after the Pt deposition, aspreviously reported by us.[37] The results indicate that the PVPA-coating on the Pt-NPs is not favorable for such a high activity. Importantly, the CO-tolerances of the two electrocatalysts were comparable,which would be due to an efficient amount of PVPA on the electrocatalyst since the PVPA is vital for the enhancement of $\mathrm{CO}$ tolerance during the MOR because the phosphorus moiety weakens the binding energy between the $\mathrm{Pt}$ and $\mathrm{CO}$ species. Thus, the $\mathrm{Pt}$ deposition onto the outer surfaces of the catalyst has an advantagefor the MOR since the sluggish MOR was enhanced and the CO-tolerance remained.The mass activity of the 
commercial CB/Ptlost about $50 \%$ after the durability test. The stable MOR of MWNT/PyPBI/PVPA/Pt was attributed to the higher durability.

\section{Conclusions}

In conclusion, we synthesized MWNT/PyPBI/PVPA/Pt by Pt-deposition onto the surfaces of the MWNT/PyPBI/PVPA, whose structure is different from MWNT/PyPBI/Pt/PVPA, in which the PVPA-coating was carried out on MWNT/PyPBI/Pt.It was revealed that the MWNT/PyPBI/PVPA/Pt showed almost no loss in the ECSA during the potential cycling in the range of $1.0 \sim 1.5 \mathrm{~V}$ vs. RHE, whilethe commercial $\mathrm{CB} / \mathrm{Pt}$ showed a $46 \%$ loss in the ECSA. Meanwhile, the CO-tolerance of the MWNT/PyPBI/PVPA/Pt evaluated from the MOR and CO stripping voltammetryindicated that the electrocatalyst has a higher tolerance towards the $\mathrm{CO}$ species than that of the $\mathrm{CB} / \mathrm{Pt}$. In addition, the MWNT/PyPBI/PVPA/Pt is more active during the MOR compared to the $\mathrm{CB} / \mathrm{Pt}$ and MWNT/PyPBI/Pt/PVPA. Preparation of such a highly durable, CO-tolerant electrocatalyst is important as an anode material for tactual use in the DMFC.

\section{Acknowledgements}

This study was supported in part by the project "Advanced Research Program for Energy and Environmental Technologies" commissioned by the New Energy and 
Industrial Technology Development Organization (NEDO), the Nanotechnology

Platform Project (Molecules and Materials Synthesis) of the Ministry of Education,

Culture, Sports, Science and Technology (MEXT), Japan and The Japan Science and Technology Agency (JST) through its "Center of Innovation Science and Technology based Radical Innovation and Entrepreneurship Program (COI Program)”.

\section{References}

[1] Koenigsmann C, Wong SS. One-dimensional noble metal electrocatalysts: a promising structural paradigm for direct methanol fuel cells. Energy Environ Sci 2011;4:1161-76.

[2] Winter M, Brodd RJ. What Are Batteries, Fuel Cells, and Supercapacitors? Chem Rev 2004;104:4245-70.

[3] Scofield ME, Koenigsmann C, Wang L, Liu H, Wong SS. Tailoring the composition of ultrathin, ternary alloy PtRuFe nanowires for the methanol oxidation reaction and formic acid oxidation reaction. Energy Environ Sci 2015;8:350-63.

[4] Gyenge E, Atwan M, Northwood D. Electrocatalysis of Borohydride Oxidation on Colloidal Pt and Pt-Alloys (Pt-Ir, Pt-Ni, and Pt-Au) and Application for Direct Borohydride Fuel Cell Anodes. J Electrochem Soc 2006;153:A150-A8.

[5] Liu BH, Li ZP, Arai K, Suda S. Performance improvement of a micro borohydride 
fuel cell operating at ambient conditions. Electrochim Acta 2005;50:3719-25.

[6] Celik C, Boyaci San FG, Sarac HI. Improving the direct borohydride fuel cell performance with thiourea as the additive in the sodium borohydride solution. Int $\mathrm{J}$ Hydrogen Energy 2010;35:8678-82.

[7] Celik C, San FGB, Sarac HI. Influences of sodium borohydride concentration on direct borohydride fuel cell performance. J Power Sources 2010;195:2599-603.

[8] Celik C, Boyaci San FG, Sarac HI. Effects of operation conditions on direct borohydride fuel cell performance. J Power Sources 2008;185:197-201.

[9] Celik C, Boyaci San FG, Sarac HI. Investigation of Ni Foam Effect for Direct Borohydride Fuel Cell. Fuel Cells 2012;12:1027-31.

[10] Iwasita T. Electrocatalysis of methanol oxidation. Electrochim Acta $2002 ; 47: 3663-74$.

[11] Kamarudin SK, Achmad F, Daud WRW. Overview on the application of direct methanol fuel cell (DMFC) for portable electronic devices. Int J Hydrogen Energy 2009;34:6902-16.

[12] Zhao X, Yin M, Ma L, Liang L, Liu C, Liao J, et al. Recent advances in catalysts for direct methanol fuel cells. Energy Environ Sci 2011;4:2736-53.

[13] Bosco JP, Sasaki K, Sadakane M, Ueda W, Chen JG. Synthesis and 
Characterization of Three-Dimensionally Ordered Macroporous (3DOM) Tungsten Carbide: Application to Direct Methanol Fuel Cells. Chem Mater 2010;22:966-73.

[14] Calvillo L, Lázaro MJ, García-Bordejé E, Moliner R, Cabot PL, Esparbé I, et al. Platinum supported on functionalized ordered mesoporous carbon as electrocatalyst for direct methanol fuel cells. J Power Sources 2007;169:59-64.

[15] Xue X, Ge J, Liu C, Xing W, Lu T. Novel chemical synthesis of Pt-Ru-P electrocatalysts by hypophosphite deposition for enhanced methanol oxidation and $\mathrm{CO}$ tolerance in direct methanol fuel cell. Electrochem Commun 2006;8:1280-6.

[16] Liu Y, Li D, Stamenkovic VR, Soled S, Henao JD, Sun S. Synthesis of Pt3Sn Alloy Nanoparticles and Their Catalysis for Electro-Oxidation of $\mathrm{CO}$ and Methanol. ACS Catal 2011;1:1719-23.

[17] Alia SM, Zhang G, Kisailus D, Li D, Gu S, Jensen K, et al. Porous Platinum Nanotubes for Oxygen Reduction and Methanol Oxidation Reactions. Adv Funct Mater 2010;20:3742-6.

[18] Berber MR, Fujigaya T, Nakashima N. High-Temperature Polymer Electrolyte Fuel Cell Using Poly(vinylphosphonic acid) as an Electrolyte Shows a Remarkable Durability. ChemCatChem 2014;6:567-71.

[19] Huang H, Wang X. Recent progress on carbon-based support materials for 
electrocatalysts of direct methanol fuel cells. J Mater Chem A 2014;2:6266-91.

[20] Polo AS, Santos MC, de Souza RFB, Alves WA. Pt-Ru-TiO2 photoelectrocatalysts for methanol oxidation. J Power Sources 2011;196:872-6.

[21] Liao S, Holmes K-A, Tsaprailis H, Birss VI. High Performance PtRuIr Catalysts Supported on Carbon Nanotubes for the Anodic Oxidation of Methanol. J Am Chem Soc 2006;128:3504-5.

[22] Yu LH, Kuo CH, Yeh CT. Poly(vinylpyrrolidone)-modified graphite carbon nanofibers as promising supports for PtRu catalysts in direct methanol fuel cells. $\mathrm{J}$ Am Chem Soc 2007;129:9999-10010.

[23] Zhou S, McIlwrath K, Jackson G, Eichhorn B. Enhanced CO Tolerance for Hydrogen Activation in $\mathrm{Au}-\mathrm{Pt}$ Dendritic Heteroaggregate Nanostructures. J Am Chem Soc 2006;128:1780-1.

[24] Zhou S, Jackson GS, Eichhorn B. AuPt Alloy Nanoparticles for CO-Tolerant Hydrogen Activation: Architectural Effects in Au-Pt Bimetallic Nanocatalysts. Adv Funct Mater 2007;17:3099-104.

[25] Dupont C, Jugnet Y, Loffreda D. Theoretical Evidence of PtSn Alloy Efficiency for CO Oxidation. J Am Chem Soc 2006;128:9129-36.

[26] Cao L, Scheiba F, Roth C, Schweiger F, Cremers C, Stimming U, et al. Novel 
nanocomposite $\mathrm{Pt} / \mathrm{RuO} 2 \cdot \mathrm{xH} 2 \mathrm{O} /$ carbon nanotube catalysts for direct methanol fuel cells.

Angew Chem Int Ed 2006;45:5315-9.

[27] Huang H, Sun D, Wang X. Low-Defect MWNT-Pt Nanocomposite as a High Performance Electrocatalyst for Direct Methanol Fuel Cells. J Phys Chem C 2011;115:19405-12.

[28] Ji K, Chang G, Oyama M, Shang X, Liu X, He Y. Efficient and clean synthesis of graphene supported platinum nanoclusters and its application in direct methanol fuel cell. Electrochim Acta 2012;85:84-9.

[29] Wang Y-S, Yang S-Y, Li S-M, Tien H-W, Hsiao S-T, Liao W-H, et al. Three-dimensionally porous graphene-carbon nanotube composite-supported PtRu catalysts with an ultrahigh electrocatalytic activity for methanol oxidation. Electrochim Acta 2013;87:261-9.

[30] Shao J-J, Li Z-J, Zhang C, Zhang L-F, Yang Q-H. A wavy graphene/platinum hybrid with increased electroactivity for the methanol oxidation reaction. J Mater Chem A 2014;2:1940-6.

[31] Liu Y, Mustain WE. High stability, high activity Pt/ITO oxygen reduction electrocatalysts. J Am Chem Soc 2013;135:530-3.

[32] Kou R, Shao Y, Mei D, Nie Z, Wang D, Wang C, et al. Stabilization of 
Electrocatalytic Metal Nanoparticles at Metal-Metal Oxide-Graphene Triple Junction Points. J Am Chem Soc 2011;133:2541-7.

[33] Yang Z, Berber MR, Nakashima N. A polymer-coated carbon black-based fuel cell electrocatalyst with high CO-tolerance and durability in direct methanol oxidation. $\mathrm{J}$ Mater Chem A 2014;2:18875-80.

[34] Yang Z, Kim C, Hirata S, Fujigaya T, Nakashima N. Facile Enhancement in CO-Tolerance of a Polymer-Coated Pt Electrocatalyst Supported on Carbon Black: Comparison between Vulcan and Ketjenblack. ACS Appl Mater Interfaces 2015;7:15885-91.

[35] Fujigaya T, Okamoto M, Nakashima N. Design of an assembly of pyridine-containing polybenzimidazole, carbon nanotubes and $\mathrm{Pt}$ nanoparticles for a fuel cell electrocatalyst with a high electrochemically active surface area. Carbon $2009 ; 47: 3227-32$.

[36] Okamoto M, Fujigaya T, Nakashima N. Design of an assembly of poly(benzimidazole), carbon nanotubes, and $\mathrm{Pt}$ nanoparticles for a fuel-cell electrocatalyst with an ideal interfacial nanostructure. Small 2009;5:735-40.

[37] Yang Z, Nakashima N. A simple preparation of very high methanol tolerant cathode electrocatalyst for direct methanol fuel cell based on polymer-coated carbon 
nanotube/platinum. Sci Rep 2015;5:12236.

[38] Xiao L, Zhang H, Jana T, Scanlon E, Chen R, Choe EW, et al. Synthesis and characterization of pyridine-based polybenzimidazoles for high temperature polymer electrolyte membrane fuel cell applications. Fuel Cells 2005;5:287-95.

[39] Ohma A, Shinohara K, Iiyama A, Yoshida T, Daimaru A. Membrane and catalyst performance targets for automotive fuel cells by FCCJ membrane, catalyst, MEA WG. ECS Trans2011;41:775-84.

[40] Grove LJ, Rennekamp JM, Jude H, Connick WB. A New Class of Platinum(II) Vapochromic Salts. J Am Chem Soc 2004;126:1594-5.

[41] Berber MR, Fujigaya T, Sasaki K, Nakashima N. Remarkably Durable High Temperature Polymer Electrolyte Fuel Cell Based on Poly(vinylphosphonic acid)-doped Polybenzimidazole. Sci Rep 2013;3:1764.

[42] Wang D, Xin HL, Hovden R, Wang H, Yu Y, Muller DA, et al. Structurally ordered intermetallic platinum-cobalt core-shell nanoparticles with enhanced activity and stability as oxygen reduction electrocatalysts. Nat Mater 2013;12:81-7.

[43] Fujigaya T, Hirata S, Nakashima N. A highly durable fuel cell electrocatalyst based on polybenzimidazole- coated stacked graphene. J Mater Chem A 2014;2:3888-93.

[44] Yang Z, Nakashima N. An Electrocatalyst Based on Carbon Nanotubes Coated with 
Poly(vinylpyrrolidone) Shows a High Tolerance to Carbon Monoxide in a Direct Methanol Fuel Cell. ChemCatChem 2016;8:600-6.

[45] Yang Z, Fujigaya T, Nakashima N. A phosphoric acid-doped electrocatalyst supported on poly(para-pyridine benzimidazole)-wrapped carbon nanotubes shows a high durability and performance. J Mater Chem A 2015;3:14318-24.

[46] Gu Y-J, Wong W-T. Nanostructure PtRu/MWNTs as Anode Catalysts Prepared in a Vacuum for Direct Methanol Oxidation. Langmuir 2006;22:11447-52.

[47] Koenigsmann C, Wong SS. Tailoring Chemical Composition To Achieve Enhanced Methanol Oxidation Reaction and Methanol-Tolerant Oxygen Reduction Reaction Performance in Palladium-Based Nanowire Systems. ACS Catal 2013;3:2031-40.

[48] Ding L-X, Wang A-L, Li G-R, Liu Z-Q, Zhao W-X, Su C-Y, et al. Porous Pt-Ni-P Composite Nanotube Arrays: Highly Electroactive and Durable Catalysts for Methanol Electrooxidation. J Am Chem Soc 2012;134:5730-3. 


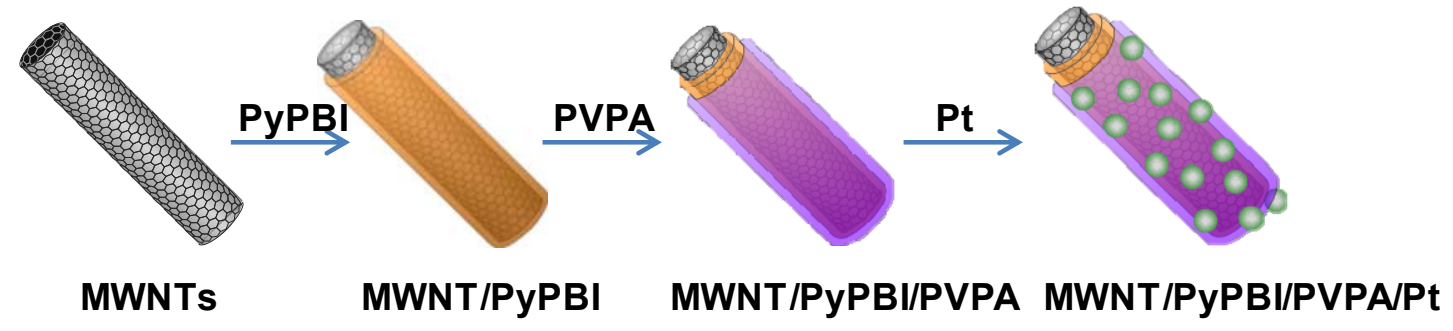

Graphical Abstract 